\title{
EL INÉDITO LIBRO SOBRE TERAPÉUTICA UROLÓGICA DEL DR. D. VICTORIANO MOLINA GARCÍA (1899-1986)
}

\author{
Mariano Pérez Albacete, Gerardo Server Pastor y Francisco Pastor Sempere?.
}

Servicio de Urología. Hospital Universitario Virgen de la Arrixaca. Murcia. Hospital de Sagunto'. Valencia. España.

\begin{abstract}
Resumen.- OBJETIVO: Dar a conocer y resaltar la obra original inédita Terapéutica Urológica del Dr. D. Victoriano Molina, urólogo valenciano de gran talla y trazar su semblanza biográfica.

MÉTODO: Lectura detenida de su tratado terapéutico y de sus publicaciones. Para componer su biografía recabamos información directa de sus descendientes y recogemos datos de compañeros que trabajaron a su lado.

RESULTADO: Recluido en el Madrid asediado durante la Guerra Civil, dedicó su tiempo a redactar un manual de consulta terapéutica de uso personal, que, una vez ultimado, constituye un excelente tratado en el que
\end{abstract}

\section{CORRESPONDENCIA}

Mariano Pérez Albacete

Hospital Universitario Virgen de la Arrixaca.

Ctra. Madrid-Cartagena

30120 El Palmar Murcia (España)

mariano.perez2@carm.es

Aceptado para publicar: 29 de mayo 2009 se reúne toda la patología urológica con sus diferentes situaciones clínicas y que establece la pauta de tratamiento médico con indicaciones precisas, enriquecido con numerosas fórmulas magistrales y preparados de la época.

El Dr. Molina, formado con el Dr. de la Peña y urólogo del Hospital de La Princesa con los Drs. Cifuentes, padre e hijo, fue incluido por el Dr. Jiménez Díaz en el Instituto de Investigaciones Médicas, como agregado de Urología, centro en el que ultimó su carrera profesional.

CONCLUSIÓN: El tratado de Terapéutica Urológica, escrito en 1938, representa un excelente e inédito texto urológico, sin parangón en la bibliografía por su contenido, prontuario que hubiese constituido un adecuado refuerzo como manual de consulta permanente en cualquier despacho de la especialidad.

Su autor, recordado por su bonhomía, sus conocimientos y su dedicación a la especialidad, se descubre gracias a esta obra, como una de las personalidades relevantes de la Urología española.

Palabras clave: Terapéutica urológica. Historia de la Urología. Semblanza biográfica. Victoriano Molina. Urología valenciana.

Summary.- OBJECTIVES: To present the unpublished original book on Urological Therapeutics of Dr. Victoriano Molina, a great urologist from Valencia, and to outline his biographical sketch.

METHODS: We read his treaty on therapeutics and his publications with detail. To elaborate his biography we obtained information from his descendants and the people who worked with him.

RESULTS: When he was locked in the besieged Madrid during the Civil war he dedicated his time to write a the- 
rapeutics manual for personal use, which when finished became an excellent treaty in which all the urological pathology was gathered with various clinical scenarios, establishing the medical treatment with precise indications, enriched with numerous magistral formulas and preparations from the time.

Dr Molina trained with Dr de la Peña and worked in Hospital de la Princesa with Drs. Cifuentes, father and son, and he was included by Dr. Jimenez Diaz in the staff of the Medical Research Institute, center in which he completed his professional career.

CONCLUSION: The treaty of Urological Therapeutics, written in 1938, represents an excellent unpublished urological text, without comparison in the bibliography due to its contents, a manual which could have bécame an adequate consultation manual in any urological office.

The author, remembered by his goodness, his knowledge and his dedication to Urology, is discovered thanks to this work as one of the relevant personalities of the Spanish Urology.

Keywords: Urological Therapeutics. History of Urology. Biography. Victoriano Molina. Urology in Valencia.

Buen urólogo, intachable profesional y recio caballero... porque así eres y así lo digo

Dedicatoria del Dr. Insausti

\section{INTRODUCCIÓN}

En la Urología española encontramos grandes profesionales entregados durante toda su vida a la especialidad, en la que descollaron dentro de su área ocupacional y que el tiempo ha dejado en el olvido. Queremos recuperar la memoria de algunas de estas personalidades y apreciar su quehacer, a la par que mostrar los medios con los que contaban para realizar su ejercicio diario para conocimiento y valoración de su labor, especialmente por las jóvenes generaciones de urólogos.

Destacamos la figura del Dr. D. Victoriano Molina, urólogo valenciano de gran talla que ejerció toda su carrera en Madrid, y desvelamos la existencia de su obra original e inédita, Terapéutica Urológica, extraordinario compendio enriquecido con su saber y con su dilatada experiencia.

\section{MATERIAL Y MÉTODO}

Lectura detenida de su tratado y de sus publicaciones. Para componer su biografía recabamos información directa de sus descendientes y recogemos datos de compañeros que trabajaron a su lado.

\section{RESULTADO}

Recluido en el Madrid asediado durante la Guerra Civil, empleó su tiempo en redactar un libro de Urología con el título de Terapéutica Urológica, con el tratamiento de las nefropatías médicas que, finalizado en octubre de 1938 y conservado cuidadosamente por su familia, lo dedicó a su maestro, D. Pedro Cifuentes, "en prueba de admiración y afecto". Lleva una cita, "debe hacerse en cada momento lo que en cada momento es necesario", máxima que refleja su proceder.

En sus cien páginas mecanografiadas y encuadernadas, con un índice de materias (Figuras 1, 2 y 3) fácilmente localizables al añadir su enumeración

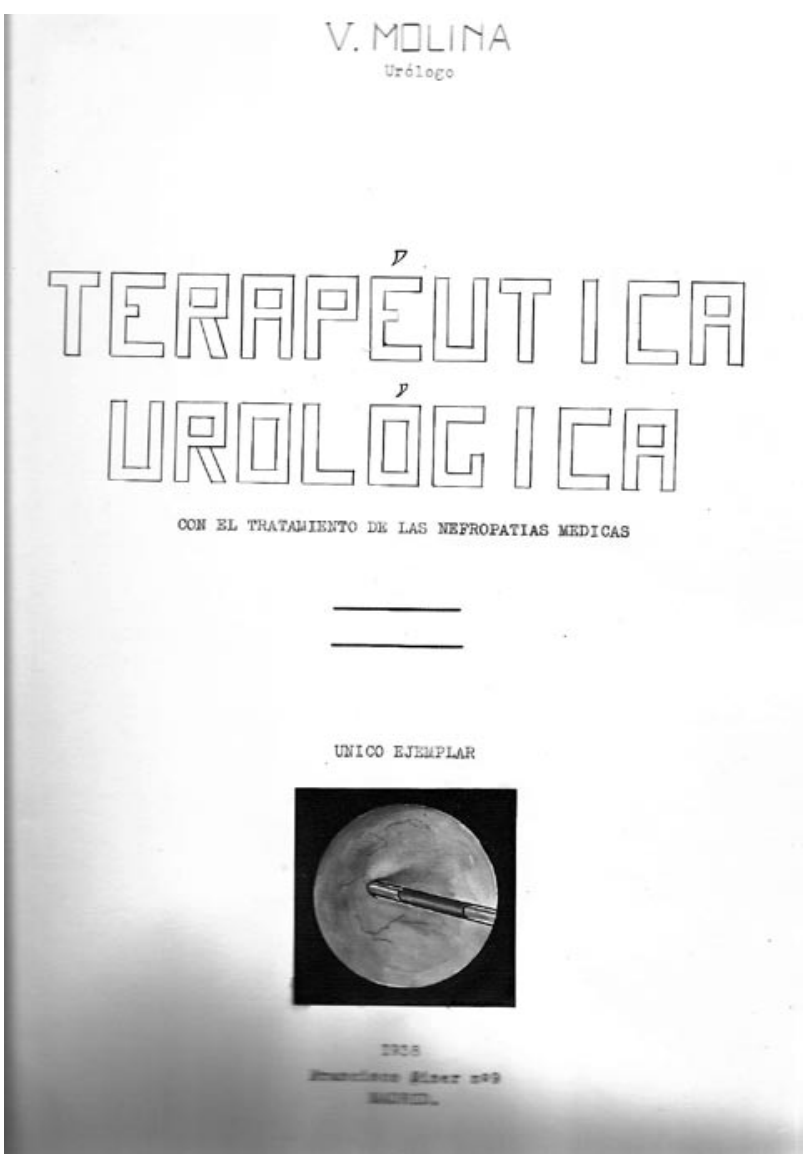

FIGURA 1. Portada mecanografiado de Terapéutica Urológica. 
paginada final, hallamos un extenso prontuario de tratamientos urológicos con una amplia y minuciosa descripción de prescripciones con fórmulas magistrales, remedios y específicos utilizados en la época para todos los procesos de la especialidad, completado con un esmerado texto en el que reseña los diversos estados clínicos que presenta la patología descrita. De inestimable ayuda para el médico práctico, en su tiempo hubiese podido constituir un gran éxito editorial dado el escaso panorama científico. Lamentablemente no llegó a publicarlo muy probablemente debido a la situación y circunstancias españolas de esos años.

Comienza con un formulario de soluciones antisépticas para lavados urológicos en el que no sólo muestra la receta magistral de dispensación sino que también incluye la relación de sus principios activos y añade la de los preparados farmacéuticos que los llevan, señala la indicación de uso con su posología y las precauciones que se deben mantener en su toma, además del régimen alimenticio y consideraciones varias para cada estado patológico; de igual modo obra con la medicación acidificante y al- calinizante de las orinas, además de con la diurética y la sedante.

Prosigue con las enfermedades médicas de los riñones, que comprenden los edemas, la uremia y la nefrosis y nefritis. Pasa a la semiología urológica en la que determina el tratamiento para la incontinencia infantil, las anurias, la bacteriuria, la quiluria, la fosfaturia, la infección urinaria en general, la uretrorragia, la espermatorrea, el priapismo, la impotencia y los trastornos vesicales de etiología nerviosa, de todos ellos analiza su forma de aparición, las causas posibles de su origen, su evolución y la terapia según la fase en que se encuentre en el momento del diagnóstico.

Las afecciones urológicas renales y ureterales quedan ampliamente clasificadas y expuestas con las anomalías, las heridas, las pielonefritis, la tuberculosis, las poliquistosis, las fístulas y sobre todo la litiasis de la que trata el cólico nefrítico y se explaya en pormenorizar todas las clases de cálculos con su etiología, apunta también los regímenes alimenticios para cada uno, el tipo de aguas recomendadas y las medicaciones precisas, sin dejar de recoger los

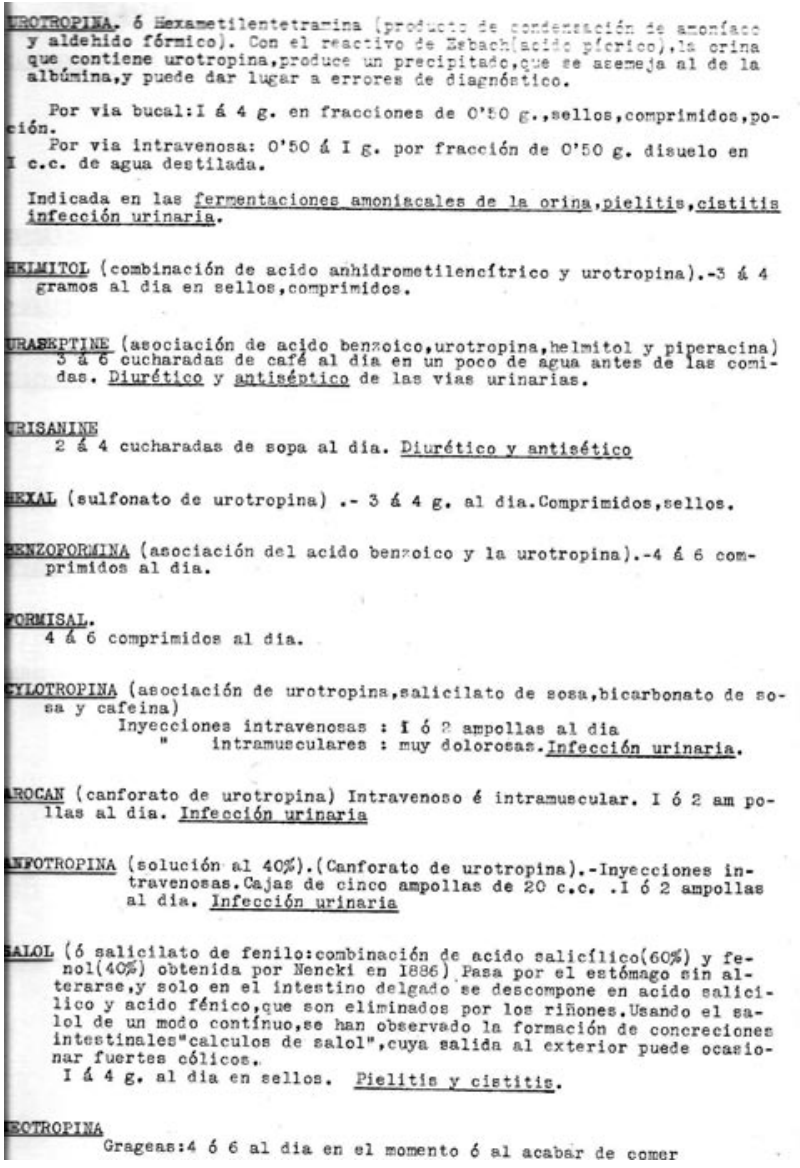

FIGURA 2. Página del libro, con fórmulas magistrales.

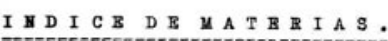

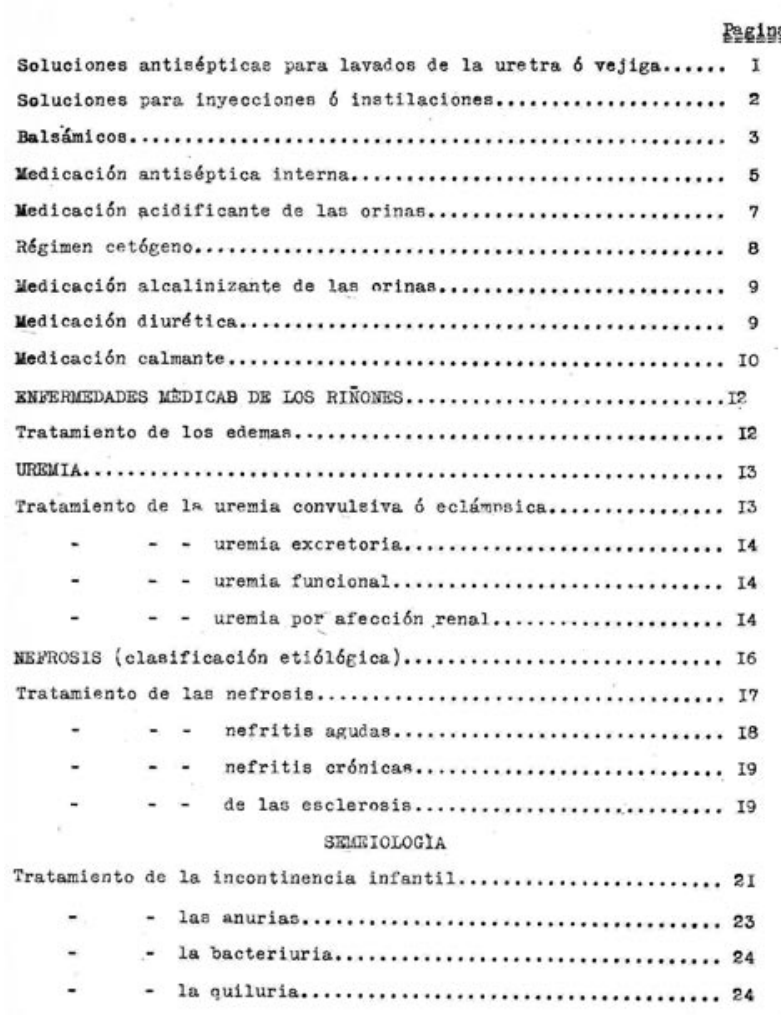

FIGURA 3. Índice del libro. 
procedimientos endoscópicos y los quirúrgicos. Del uréter anota las ureteritis tuberculosas, las estenosis y las compresiones por tumor, las fístulas, el prolapso y las anomalías de implantación.

Repasa los procesos del tramo urinario inferior, especialmente los cuadros de cistitis, con instrucciones para atender sus formas de presentación según su codificación histológica, además de la tuberculosis, la gangrena, las úlceras y la bilharziosis; un capítulo especial lo constituyen el pólipo y el cáncer de la vejiga, para los que indica la electrocoagulación, el radium y la radioterapia profunda, sin excluir la cirugía parcial o total. Con las pericistitis, las diferentes fístulas urinarias, el manejo de las piedras y los métodos de extracción de los cuerpos extraños, que se pueden ubicar en el interior uretral o de la cavidad vesical, se ultima esta parte.

De las uretritis aborda la gonocócica con múltiples tratamientos médicos, tanto preventivos como curativos aplicables en sus distintas fases evolutivas desde los procesos agudos iniciales hasta los complicados, a lo que suma las pruebas para confirmar la curación. En la blenorragia crónica, masculina o femenina, muestra las consecuencias de su progresión y cómo se debe actuar. Las estrecheces uretrales son otro apartado en el que manifiesta un amplio conocimiento y experiencia en las maneras de resolverlas, reseña sus variadas formas con meticulosidad y la técnica de dilatación progresiva en la que se ayuda, en las infranqueables o complejas, de remedios tradicionales como baños de asiento, enemas, calor, etc., y de específicos de formulación antiespasmódi- ca o antinflamatoria para facilitar el paso de bujías o beniqués $y$, si es preciso, recurre a la dilatación electrolítica, o a la uretroscopia, para finalmente acceder a la uretrotomía interna o externa.

En la patología prostática se detiene en los cuadros de prostatitis aguda y crónica en los que igualmente apreciamos un gran dominio de su terapéutica. La hipertrofia benigna de la próstata la atiende con líneas preventivas en su comienzo y da normas higiénicas, alimenticias y de hábitos generales, seguido todo ello de la prescripción de numerosos preparados, continúa, en relación con la clínica dominante, con qué hacer en los periodos de retención urinaria incompleta con o sin distensión vesical, especifica las diversas complicaciones que puede presentar, para posteriormente indicar la prostatectomía; explica también el tratamiento del cáncer de próstata con radio o radiumterapia $y$, en hoja aparte en los años cincuenta, agrega la utilización de estrógenos como el Estilbén. Habla de las afecciones del pene en las que abarca la luxación, la estrangulación por cuerpos externos, la induración plástica, la sífilis, el chancro, la linfangitis y la gangrena.

Acaba la obra con la preparación general del paciente para la cirugía, esencialmente del diabético y también especifica la administración de estimulantes, de tónicos, de vitaminas y de reconstituyentes generales (Figura 4).

Nació el Dr. D. Victoriano Molina (Figura 5) en el seno de una familia de origen valenciano el 6 de julio de 1899 en la población alicantina de Pego,

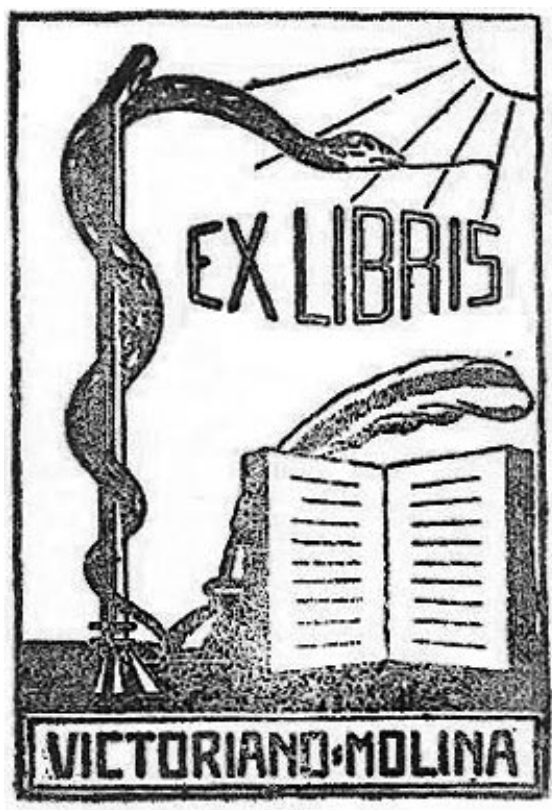

FIGURA 4. Ex libris del Dr. Molina.

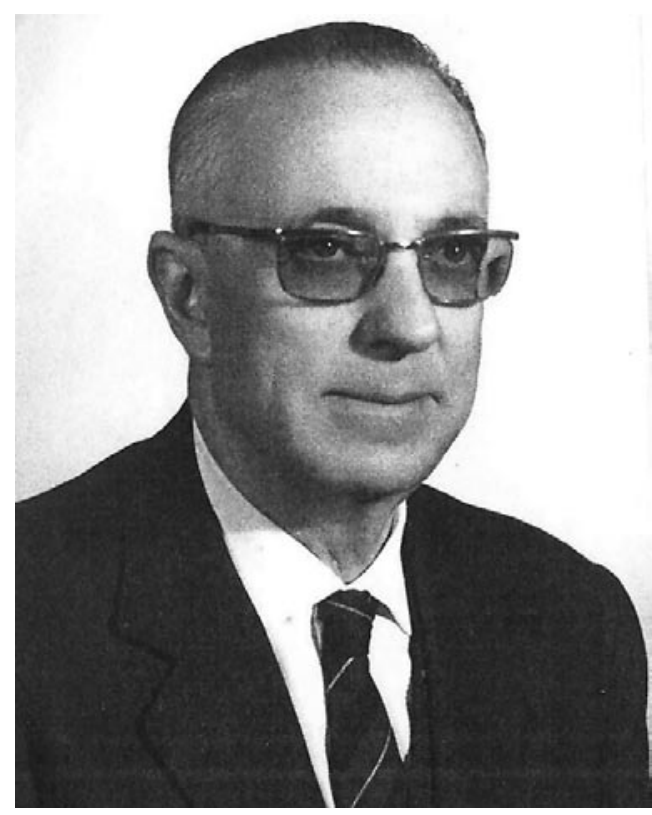

FIGURA 5. Dr. D. Victoriano Molina García. 
donde su padre era notario. Obtuvo el grado de bachiller en el Instituto General y Técnico de Alicante el 26 de junio de 1917. Estudió Medicina en la Facultad de Valencia, fue alumno interno durante el curso 1918-19 y en octubre de 1922 realizó el examen de licenciatura. Con un buen expediente marchó a Madrid para matricularse en los cursos del doctorado $y$, decidido a acrecentar sus conocimientos y a especializarse, entró en el Hospital Clínico de San Carlos, en la recién establecida cátedra de Urología, donde estuvo formándose por espacio de dos años con el Dr. D. Leonardo de la Peña, hacia quien conservó un gran aprecio toda su vida.

En 1924 ingresó en el Hospital de La Princesa, en el servicio de Urología que organizó el Dr. D. Pedro Cifuentes Díaz, con quien aprendió la patología quirúrgica y con quien colaboró en los cursos de Urología que impartía y llegó a ser un gran cirujano y su principal ayudante. Leyó el 30 de junio de 1925 su memoria de tesis, La uretrotomía interna, califica- da con sobresaliente y de la que enseñamos unos espléndidos dibujos efectuados por él en los que muestra la "sonda olivar acodada", diseñada por el Dr. D. Pedro Cifuentes, para franquear una estrechez uretral y diferentes uretrotomos (Figuras 6 y 7 ), prosigue sus prácticas sobre bacteriología en el Instituto Provincial de Higiene durante el bienio 1925-26, que, como anécdota, visitó Alfonso XIII al que personalmente le mostró en el microscopio un bacilo de Koch. En 1927 figura como corresponsal en Madrid del diario La Correspondencia de Valencia (Figura 8).

El Dr. Jiménez Díaz, catedrático de Medicina Interna en la Facultad de Medicina de Madrid desde 1927, concibe la idea de unir la asistencia clínica con la docencia y la investigación y logra fundar el Instituto de Investigaciones Médicas de la Universidad Central, con la colaboración de grandes personalidades de la Medicina española como Grande Covián, Barreda, de Castro, Arjona, Miñón, Vivanco... por señalar a algunos de los más significativos. En 1932
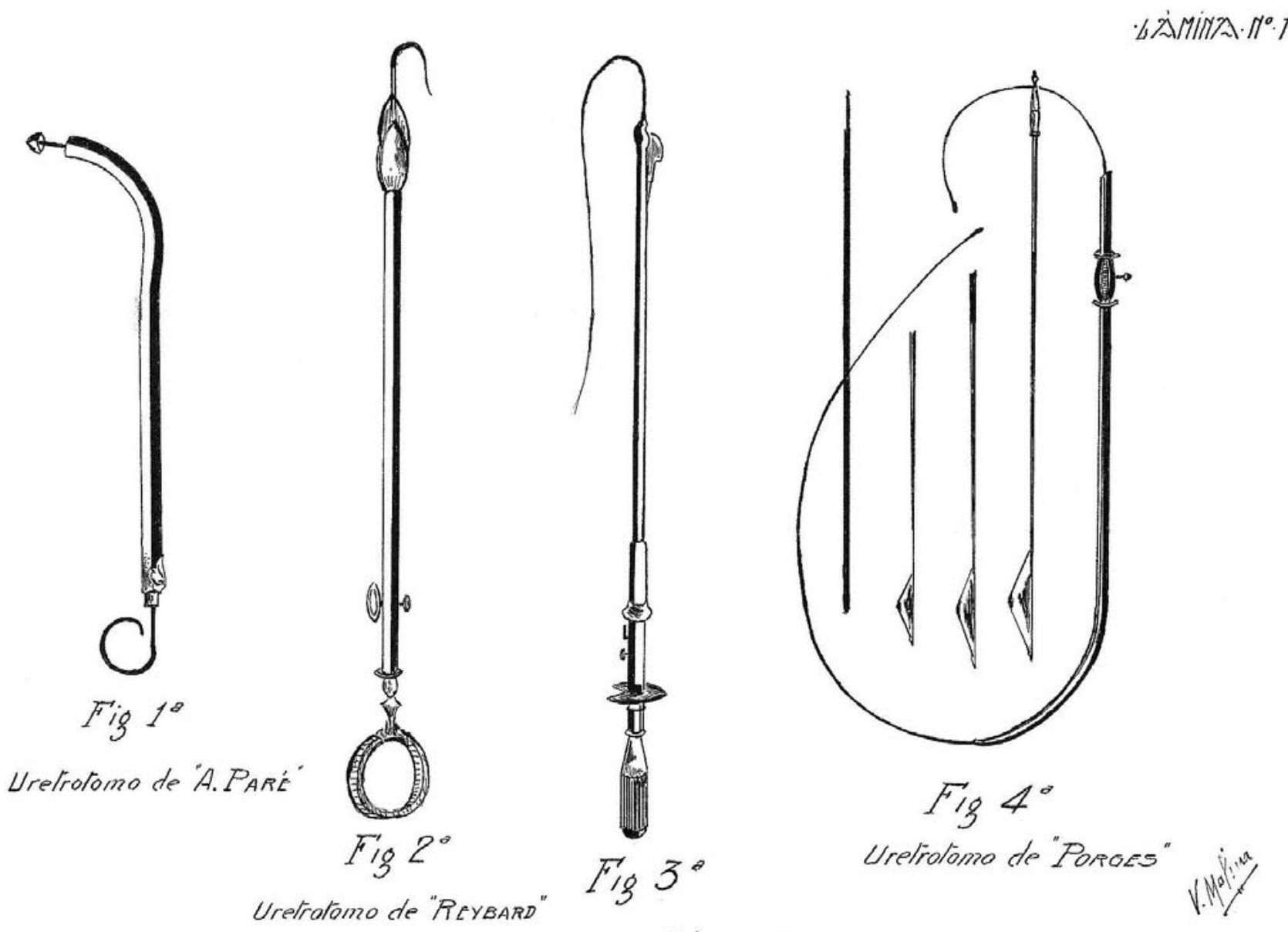

Uretrotomo de "CiviaLE"

FIGURA 6. Dibujo de diversos uretrotomos. 

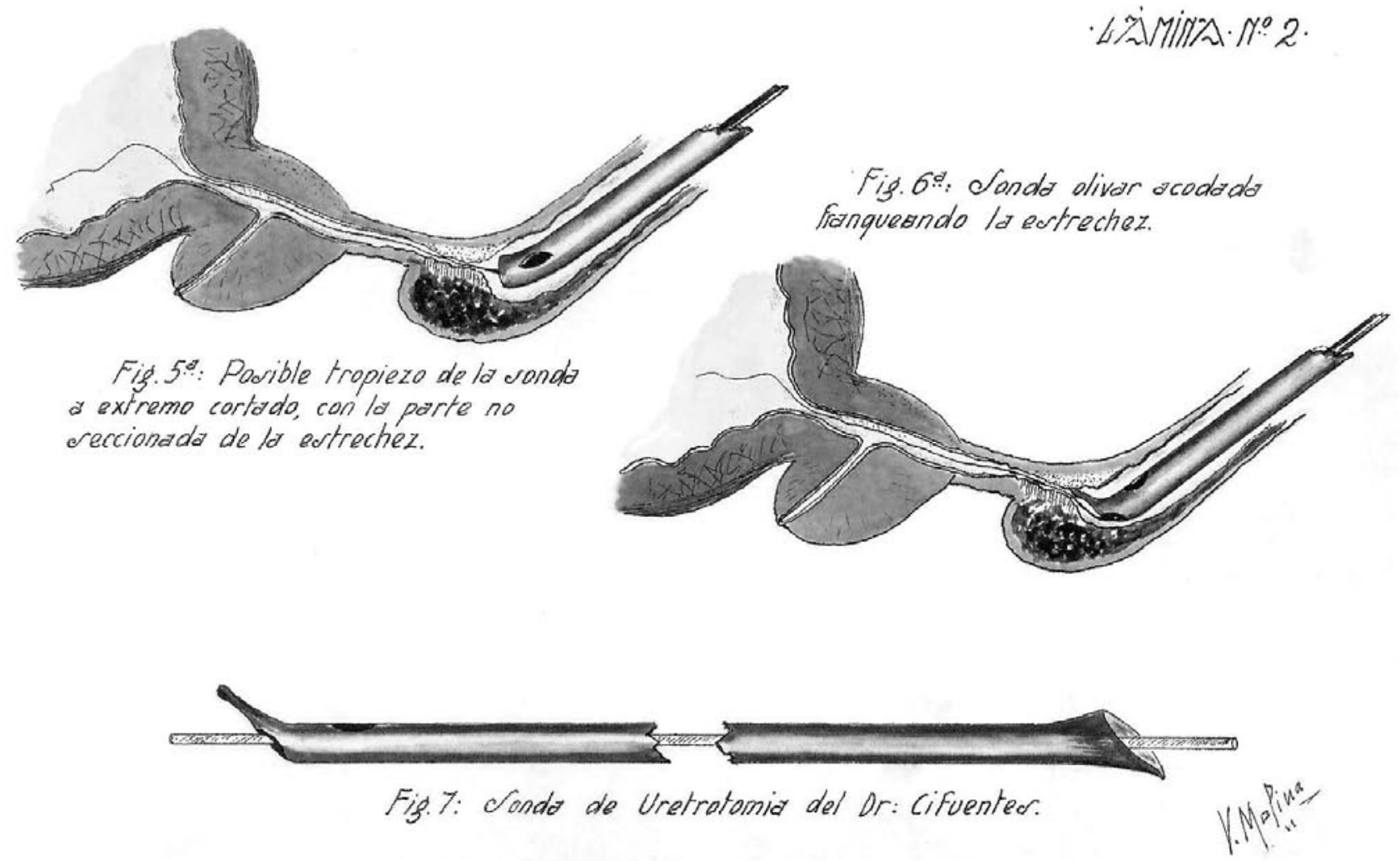

FIGURA 7. Esquema de una estenosis uretral.

incluye al Dr. Victoriano Molina como miembro por el valor de su quehacer profesional, con derecho a discutir y presentar comunicaciones en las sesiones clínicas vespertinas de los martes, en las que, en reiteradas ocasiones, demostró su preparación y valía lo que hizo que estuviese ligado toda su vida a la Institución.

Al comienzo de la Guerra Civil alegó padecer un ulcus duodenal y, de este modo, evitó ser movilizado, llevó un diario íntimo en el que recoge la vida en el Madrid sitiado y las tribulaciones padecidas para poder atender a los pacientes en el Hospital a la par que escribía su tratado; a la finalización de la contienda continúa con su asistencia clínica en el hospital de La Princesa y, en 1950, al hacerse cargo del servicio el Dr. Cifuentes Delatte, se mantiene a su lado como su mentor en el quirófano y como hombre de confianza, dadas su excelente preparación urológica y su habilidad como cirujano (Figuras 9 y 10 ).

En 1955 el Instituto de Investigaciones Médicas se agrega al Instituto Rubio, ubicado en la Moncloa, se inicia con ello la creación de la Clínica de la Concepción en la que el área quirúrgica conserva el nombre del Dr. D. Federico Rubio y a la que el Dr. Molina se incorpora como agregado de Urología. En el centro, convertido en 1963 finalmente en la
Fundación Jiménez Díaz, prosiguió su ejerció hasta su retiro en 1969.

Fue miembro de la Asociación Española de Urología (AEU) en 1925, en 1932 elegido vocal primero de la junta directiva, reelegido en 1935 y, en 1945 , tras su reestructuración después de la guerra, designado vocal segundo. Participó en los congresos de la Asociación desde el VII y I Hispano Portugués de Urología celebrado en Lisboa en 1925, con comunicaciones múltiples e intervino como ponente invitado en diversas ocasiones en las Sesiones Científicas mensuales que la AEU sostenía en Madrid. En 1933 comienza a editarse la Revista Española de Urología, órgano oficial de la AEU, cuya directiva lo nombró, junto con el Dr. Hidalgo y Fernández Caro, secretario de redacción, encargados de su edición (Figura 11).

En 1947 fue elegido socio de la Internacional de Urología. En 1978 fue nombrado Miembro de Honor de la Asociación Española de Urología en reconocimiento a su labor y dedicación urológicas.

Sus trabajos han quedado recogidos sobre todo en Los Progresos de la Clínica, en Revista Española de Cirugía y Urología, en Revista Española de Urología y en Archivos Españoles de Urología. 


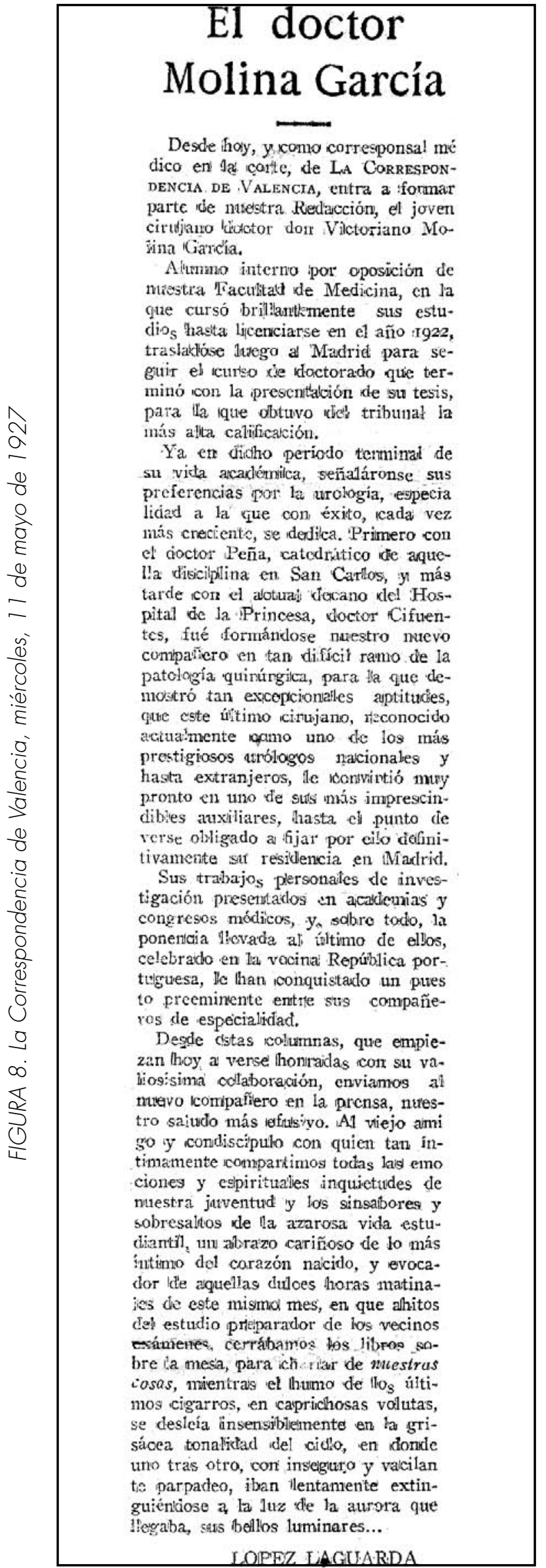

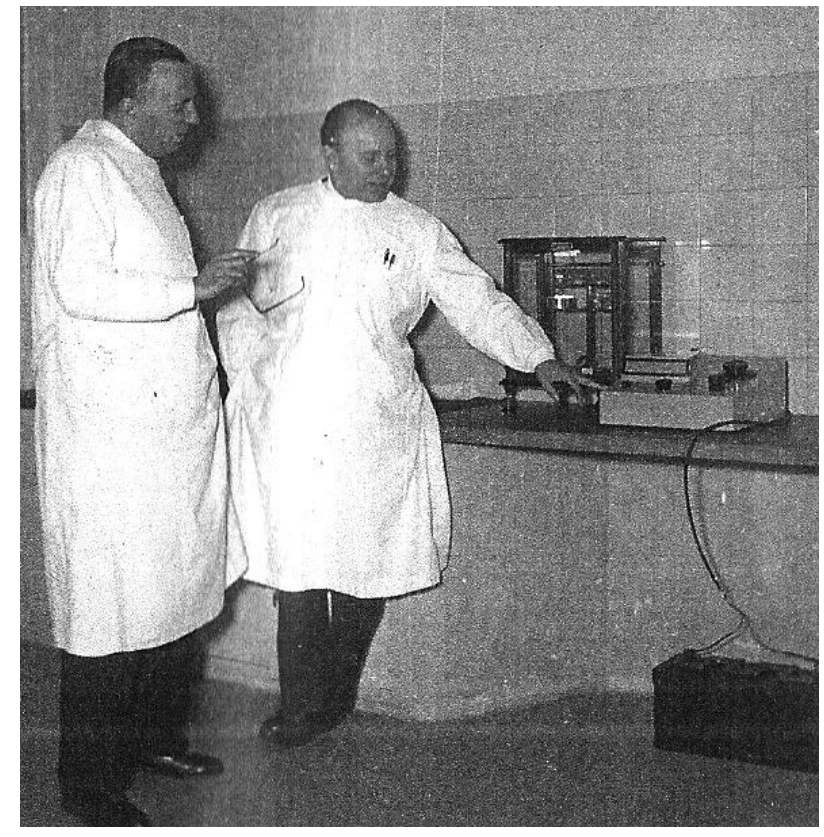

FIGURA 9. El Dr. Cifuentes Delatte le enseña un aparato.

Reseñamos algunos de los que hemos localizado:

- Pionefrosis tuberculosa bien tolerada. Rev. Esp. Cir. Uro, 1931, XII (1): 1-7.

- Anomalía ureteral doble. Rev. Esp. Cir. Uro, 1931, XII (2): 105-109.

- Quiste hidatídico de riñón. Rev. Esp. Urología, 1933, I (2): 88.

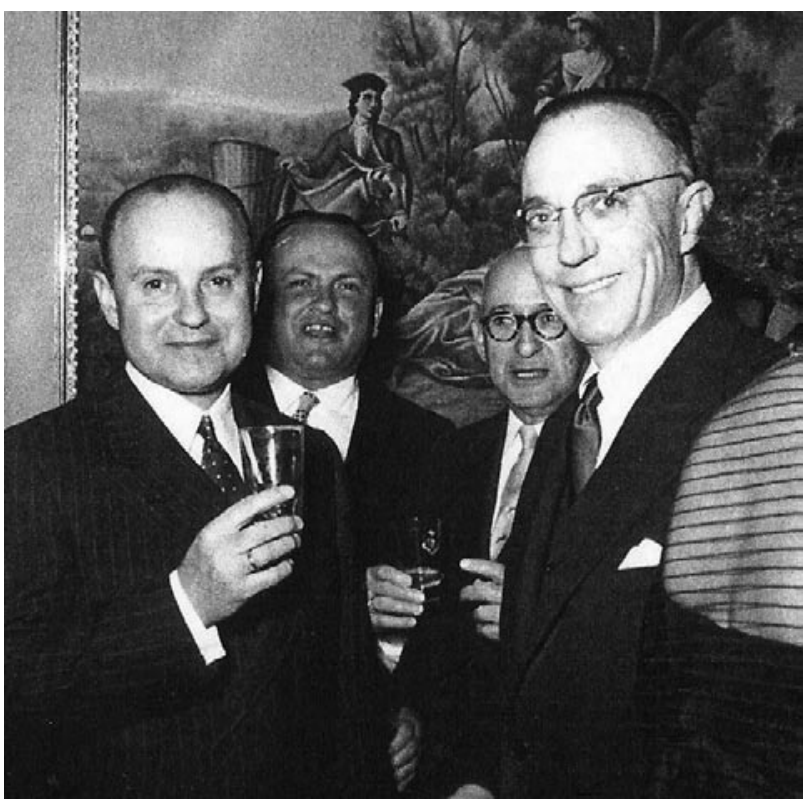

FIGURA 10. Con el Dr. Cifuentes Delatte, en una reunión. 


\section{REVISTA ESPAÑOAA DE UROLOGIA}

PUBLICACION TRIMESTRAI.

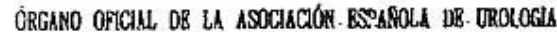

COMITE : DIRECTIVO:

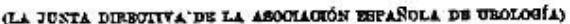

Dr. Inidro-8molnez Covise.
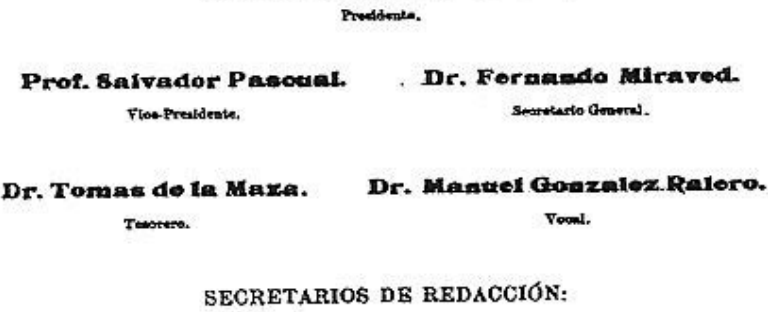

Dr. Victoriano Motian. voes.

Dr. Aguatin HAaigo. Becretarto de Ateat.

FIGURA 11. Revista Española de Urología, 19331936, en la que figura como vocal secretario de redacción.

- Cálculos uretro vesicales. Rev. Esp. Urología, 1934, II (1): 20.

- Adenomas y quistes hidatídicos renales. Arch. Esp. Urol. 1944, (2): 150-158, (Figura 12).

Por las tardes atendía a su clientela privada (Figura 13) en su domicilio, sito en la calle Martínez Campos, 9; casado con Dó. Amparo Monmeneu, médica también, de ascendencia valenciana y nacida en Cartagena, donde su padre era médico de la Armada, con la que tuvo cuatro hijas, su vida estaba consagrada por entero a su profesión y a su familia. Artista consumado, le gustaba tocar la guitarra y el piano, que aprendió de oído ya que no llegó a estudiar música. Magnífico dibujante, pintaba al óleo y ganó la medalla de plata en la primera exposición de médicos artistas organizada con motivo del VIII Congreso Internacional de Cirugía desarrollado en Madrid en 1952. Atendió a D. Santiago Ramón y Cajal, al que colocó una sonda tras un episodio de retención aguda de orina, y quien, en reconocimiento, le dedicó su fotografía (Figura 14) (al Dr. D. Victoriano Molina en testimonio de alta consideración y de cordial simpatía. Su compañero y amigo, S. Ramón y Cajal, rubricado. Madrid 13 de febrero de 1934). Amante de la fiesta nacional era amigo del gran torero madrileño Marcial Lalanda (1903-1990).
CLINICA DE UROLOGA DEL HOSPITAL DE LA PRINCESA (MADRID)

Director: Dr. Pedro Cifuentes.

\section{ADENOMAS Y QUISTE HIDATIDICO RENALES}

\section{VICTORIANO MOLINA GARCIA}

En una comunicación que presentamos a la Asociación Española de Urología, en junio de 1933, sobre quiste hidatídico renal, señalábamos la poca frecuencia de esta afección y hacíamos notar que la localización en el riñón, según promedio sacado de diversas estadísticas, era el 4 por 100 de todos los quistes hidatídicos del organismo.

Las observaciones de adenomas de riñón son aún menos frecuentes; constituyen hallazgos de autopsias, y aunque WEICHSELBAUM y GREENISH dicen encontrarlos en el 6 por 100 de las practicadas a sujetos por encima de los veinte años, AlbarRán afirma que su frecuencia es notablemente menor, ya que en 588 neoplasias de riñón, de las que se hizo examen histológico en 529, sólo se encontraron diez adenomas en adultos y tres en niños, es decir, algo menos de un 2,5 por 100 .

Desconocemos si en España han sido publicadas, como hallazgos operatorios, observaciones de adenomas renales; creyendo que puede tener algún interés dar a conocer el aspecto de los mismos, nos decidimos a publicar la siguiente observación, acompañando las fotografías de la picza operatoria, cuyo estudio histológico se hizo en el Instituto Cajal por el profesor D. FERnANDo DE CASTro, al que expresamos desde aquí nuestro agradecimiento por su valiosa ayuda.

FIGURA 12. Trabajo publicado en Archivos Españoles de Urología, 1944, (2): 150-58.

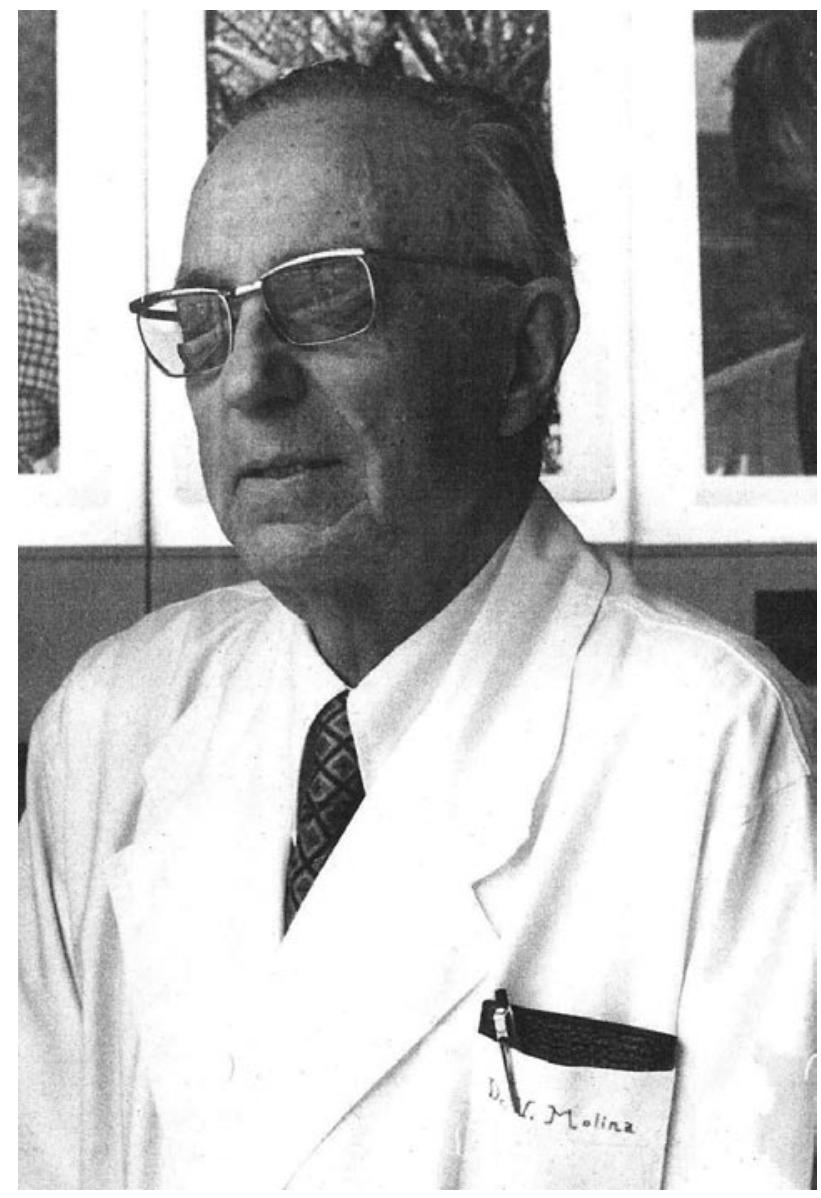

FIGURA 13. El Dr. Molina en su despacho. 


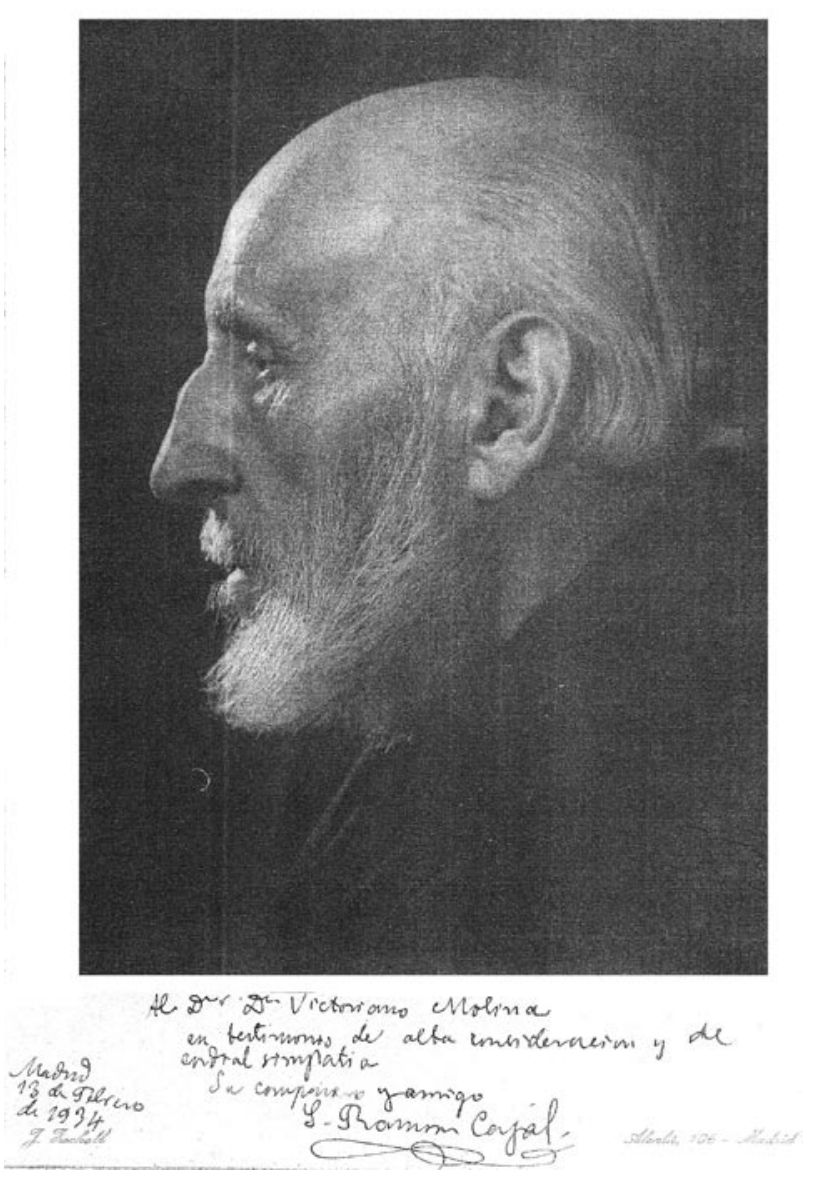

FIGURA 14. Foto dedicada del Dr. Ramón y Cajal.

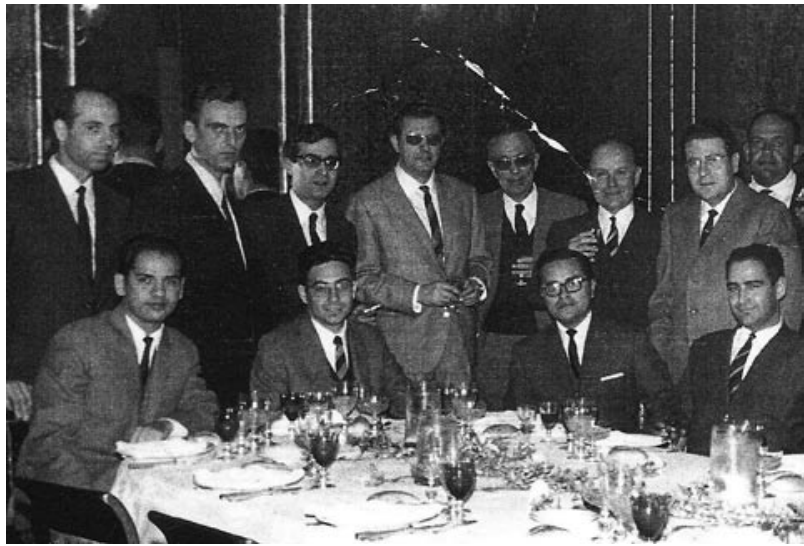

FIGURA 15. Con un grupo de compañeros. De pie, de izquierda a derecha, Drs. Escudero Barrilero, Arocena Lanz, Zaragozá Orts, Sánchez Salvador, Victoriano Molina, Cifuentes Delatte, Alférez Villalobos; detrás, el analista D. Bienvenido Esteban y, sentados,

Drs. Leónidas Cerrud Cerrud, de Panamá, Nieto

García, Núñez Chavez, de Perú, homenajeado en su cena de despedida y Pastor Sempere.
Sus coetáneos (Figura 15) lo retratan como hombre abierto, amable, de trato agradable y simpático, de fina ironía y salidas oportunas, buen compañero y amigo, con sólida formación urológica y habilidad quirúrgica, querido y respetado por sus pacientes, padre y esposo ejemplar. En Pego lo han reconocido como personaje ilustre del pueblo. Falleció en Madrid, el día 13 de noviembre de 1986, a los ochenta y siete años de edad.

\section{CONCLUSIÓN}

Descubrimos, en el tratado de Terapéutica Urológica del Dr. Molina, escrito en 1938, un excelente e inédito compendio urológico, interesante y consumado manual para tener a mano en el despacho, para la consulta terapéutica permanente, ojearlo y ajustar la prescripción ante el enfermo. Obra de extraordinaria utilidad y atractivo, única en su género, sin parangón en la bibliografía por su exposición y contenido.

Su autor, recordado por cuantos lo trataron por su bonhomía, sus grandes conocimientos, su preparación y su dedicación exclusiva a la especialidad, gracias a esta obra se descubre como una de las personalidades relevantes de la Urología española.

\section{BIBLIOGRAFÍA Y LECTURAS RECOMENDADAS ( ${ }^{*}$ lectura de interés $y^{* *}$ lectura fundamental)}

**1. Insausti Cordón J L. Compendio histórico de Urología española y de su Asociación. Ponencia al IV Congreso Iberoamericano y XLVII Español de Urología. Acapulco, septiembre de 1982.

2. Reuniones y Congresos, S A (REYCOSA), 1982, pp. 106-7. Madrid.

*3. Pérez Albacete M. Fundación y desarrollo de la Asociación Española de Urología. En Historia Biográfica y Bibliográfica de la Urología Española, pp. 62. Edicomplet, 2002, Madrid. 